Research Article

\title{
Assessing the Knowledge of Scabies Among the Women of a Rural Community at Lahore
}

\author{
Naeema Akbar ${ }^{1 *}$, Asif Hanif ${ }^{1}$, Muhammad Amir Gilani ${ }^{1}$, Samina Yasmin ${ }^{2}$ \\ ${ }^{1}$ Afro Asian Institute, Lahore, Punjab, Pakistan \\ ${ }^{2}$ Lahore School of Nursing, The University of Lahore, Pakistan
}

\section{Article Information}

Received: 09 December 2019

Revised version received: 17 January 2020

Accepted: 19 January 2020

Published: 27 January 2020

Cite this article as:

N. Akbar et al. (2020) Int. J. Soc. Sc. Manage. 7(1): 30-37. DOI: $\underline{10.3126 / \text { ijssm.v7i1.27407 }}$

\section{*Corresponding author}

Naeema Akbar,

Afro Asian Institute, Lahore, Punjab, Pakistan

Email: Naeemaashraf01@gmail.com

Peer reviewed under authority of IJSSM

(C) 2020 International Journal of Social Sciences and Management

\section{OPEN 0 ACCESS}

This is an open access article \& it is licensed under a Creative Commons Attribution Non-Commercial 4.0 International (https://creativecommons.org/licenses/by-nc/4.0/)

Keywords: Scabies; Knowledge of Scabies; Women of Gajumatta Community Lahore

\begin{abstract}
Background: scabies is endemic in most of the mountainous areas of Pakistan, the crowded and unhygienic conditions in IDP (Internally Displaced Persons) camps immediately after the earthquake was the ideal environment for a full blown outbreak of epidemic proportions.
\end{abstract}

Objective: The purpose of this study was to assess Knowledge of scabies among the women of a rural community at Lahore.

Methodology: Descriptive cross sectional study design was conducted to assess the Knowledge of scabies among the women and a sample size of $\mathrm{n}=75$ participants were selected for this study through convenient sampling. Data was collected from the women at Gajjumatta community Lahore.

Result: The main findings were as following. 93.3\% of the participants knew that scratching effect causes to Scabies, $73.3 \%$ had knowledge that Skin is the main affected organ involved in scabies and $86.7 \%$ had knowledge that itching at night and feeling heat is the main sign of scabies

Conclusion: The purpose of this study was to assess Knowledge of scabies among women at Gajumatta in Lahore. Overall result shows a good knowledge among women of Gajumatta community.

\section{Introduction}

The term Scabies was derived from the Latin word "Scabere" which means "to scratch". This is colloquially called as seven-year itch. It is a contagious skin infection that occurs among human and other animals. It has been classified by WHO as a water related disease because it is caused by a tiny and usually not directed visible parasite. The mite Sarcoptes scabei, which burrows under the host's skin. This usually causes intense allergic itching. The infection in animals caused by different but related mite species is called Sarcoptes Mange.

The disease may be transmitted from objects but is most often transmitted by direct skin to skin contact. Initial infection requires 4-6 weeks to become symptomatic. Crusted Scabies previously known as Norwegian scabies is a more severe form of the infection often associated with immunosuppression 
Scabies is a parasitic skin infestation caused by the mite Sarcoptes scabei var hominis. It occurs worldwide, and as many as 300 million people may be affected. Scabies infestation occurs in people of both sexes and all ages irrespective of ethnic group or socioeconomic status, being most common in conditions of overcrowding, poverty and poor hygiene (Sule et al., 2015)

The morbidity statistics of scabies peaks among children especially among infants and school age and among those residing at slums. In our country the environmental barriers such as high population density, lack of environmental sanitation, contamination of water and soil etc. plays a major role behind the occurrence of scabies. Lack of public awareness and even poor economic and educational background also raises the amplitude of this health burden. Eradication of this health problem is not an easy task but a lot of ventures can be done by the department of health to establish a better preventive and promotive health care.

One study conducted in Pakistan reported almost 7\% morbidity due to skin and eye infection in children reporting to health facilities. Even though scabies is endemic in most of the mountainous areas of Pakistan, the crowded and unhygienic conditions in IDP camps immediately after the earthquake was the ideal environment for a full blown outbreak of epidemic proportions. With the dismantling of most of the camps, the population moved back to their respective villages. With living conditions similar to those in the camps, an absence of essential utilities like water and proper sanitation, and peculiar weather conditions, scabies has spread in practically every village from all three tehsils of Mansehra (Mumtaz et al., 2014)

Skin related epidemics are the causes of $14 \%$ of all contagious diseases in India. Among all contagious skin diseases scabies accounts for $28 \%$. Scabies is most prevalent in Bihar, Assam \& Orissa states. In fact scabies is not a lethal illness timely prevention and management of the problem are the vital interventions need to be carried out to avoid further spread (Patrick et al., 2007).

Buehlmann et al. (2009); conducted a study in Basel; Switzrland. They investigated the outbreak of scabies in an intensive unit of university hospital to establish effective control measures against the transmission of scabies. The result showed that children with in a mean age of 3.1 years were mostly affected. A total of 1,640 exposed individuals underwent preemptive treatment. The study concluded that crusted scabies resulted in high attack rates among household contacts. Timely institution of hygienic precautions with close monitoring is essential for control of an outbreak (Buehlmann et al., 2009)

Patel et al. (2010) conducted a clinical study among the children up to the age of 14 in the west part of India. There were a total of 390 boys and 310 girls. They found that the majority of skin conditions are transient. The most common dermatosis found were having infectious etiology (38.43\%). Incidence of Scabies was (5.32\%), Impetigo (11.13\%) and pyoderma $(8.9 \%)$. They were the most prevalent dermatosis found in the study (Patel et al., 2010)

Strong $\mathrm{M}$ and Johnstone $\mathrm{P}$ published an article in the Dermatology therapy journal. The article describes that the prevalence of scabies in more the areas of poor sanitation, overcrowding and social disruption and is endemic in many resource poor countries. The global prevalence of scabies is estimated at 300 million cases but the level of infection varies between countries and communities the infection can spread from person to person through skin contact including sexual contact. The problem is more prevalent in developing countries like India, Bangladesh, Sri Lanka etc... Timely preventive measures need to be carried out as emergency interventions (Strong \& Johnstone, 2011).

Hay et al. (2012) conducted a study in international child health university of Melbourne, Australia. This study reviewed the current position of scabies with regard to its complications and control in resource poor countries. The study found that scabies remains one of the commonest skin diseases seen in developing countries. This condition affects families. It has greatest impact on young children. The infection is associated with secondary bacterial infection caused by Group A Streptococci and Staphylococcus Aureus. The burden of disease is compounded by Nephritis, Rheumatic fever and Sepsis in developing countries (Hay et al., 2012).

Rana et al. (2007) conducted a population based study in Indian state Tamil Nadu to assess the knowledge of public regarding Scabies and its management. They also analysed the attachment of the victims towards various scabies treatment strategies. They found that among 1260 samples only $20.6 \%$ had adequate knowledge regarding scabies and its management. Around $14.56 \%$ individuals had previous exposure to scabies. $33.4 \%$ of the samples wrongly reported that scabies is a non-curable disease. They realised that around $46.7 \%$ victims are currently following appropriate anti - scabies prophylaxis that includes allethrin, permethrin and ivermectin. The researchers concluded that rural communities require more information and education regarding skin related contagious diseases and their management measures (Rana et al., 2007)

Rathi et al. (2001) conducted a study to assess the Awareness about scabies among general medical practitioners of Karachi, Pakistan. A pre-tested questionnaire survey was conducted among 200 general practitioners through a cross-sectional study design and a descriptive analysis was performed. Present study showed that a substantial number of general practitioners have inadequate knowledge regarding causative organism of scabies. If responding correctly to $75 \%$ of questions 
asked, is taken as the criterion for satisfactory awareness, only $36 \%$ of general practitioners had a satisfactory level of awareness. There was no effect of increasing age or years of experience on the level of awareness. The study concluded that there is a general lack of knowledge regarding various aspects of scabies among general practitioners. Therefore, active intervention is required to improve their awareness (Zeba, Shaikh, Memon, \& Khoharo, 2014).

Lapeere et al. (2008) conducted a survey among general practitioners and dermatologists in the region of Ghent, Belgium, to explore their knowledge on scabies. Information on the treatment advice given and the frequency of reporting scabies to the Health Inspection was also collected. The scores on the knowledge test were of an acceptable level in both general practitioners and dermatologists (median score $59 \%$ and $79 \%$ respectively). The study found that profession (dermatologist versus general practitioners), the number of years of experience and the estimated number of scabies patients per year had a significant effect on this score. Permethrin cream, currently regarded as the standard treatment, is prescribed as the only treatment for scabies by half of the general practitioners and dermatologists. Almost $50 \%$ of the general practitioners and dermatologists indicated they rarely or never report scabies to the health Inspection (Lapeere et al., 2008)

\section{Dependent Variable}

Knowledge level of Women regarding Scabies.

\section{Independent Variables}

Age, gender, educational status, exposure to previous educational programme on scabies, family history of scabies etc...

\section{Research Problem}

Scabies occurs worldwide, and as many as 300 million people may be affected. It is also very common in Asian Countries such as India and Pakistan. Among all contagious skin diseases scabies accounts for $28 \%$ in India. Lack of Knowledge, attitude and poor practices makes the conditions worse. Therefore, it needs to be solved in terms of giving awareness to the community people.

\section{Significance of the Study}

The disorders of skin usually create more psychological discomforts among the patients associated with body image disturbances. These problems affect the self-concept and esteem of a person. The impact of skin related contagious diseases are worsening in our country day by day. India holds the $7^{\text {th }}$ position among the countries with highest prevalence of scabies in the world. Approximately 25 million of Indian population is affected by this health burden.

The global prevalence of scabies is estimated at 300 million cases but the level of infection varies between countries and communities. The infection can spread to person to person through direct skin contact including sexual contact. It also has greatest impact on young children the burden of disease is compounded by nephritis, rheumatic fever and sepsis in developing countries.

\section{Objectives}

To assess the level of knowledge among women about Scabies at Gajumata community of Lahore

\section{Research Question}

What are the level of knowledge among women about Scabies at Gajumata community of Lahore?

\section{Methodology}

\section{Study Design}

Quantitative Descriptive study design was used in this research to assess the Knowledge of Scabies among the Mothers of Children at Gajumata Community of Lahore. The descriptive study is being used because it helps to get information about what the actual proportion of Scabies Knowledge was.

\section{Duration of Study}

The study took 2-3 months for completion.

\section{Study Setting}

Data was collected from the female of a community of Lahore named Gajjumatta

\section{Research Participants}

Women of Gajjumatta.

\section{Study Population}

The population under study were the women at the Gajumata Community. Gajumata Community is one of the Rural Low educated, Low Socioeconomic communities of Lahore. Here in this community the chances of Communicable diseases were very high because of the low standards of living as compare to other regions of Lahore

\section{Inclusion Criteria}

Women between 15-65 years of age

women can read and write English or Urdu.

women who had no any psychiatric problems or sensory impairment.

\section{Exclusion Criteria}

women who were not willing to participate in the study.

women who were not available at the time of study.

women who had no any psychiatric problems or sensory impairment.

\section{Sample Size}

The sample will be collected through convenient sampling.

$>$ The sample size will be calculated by Slovin's formula. $\mathrm{n}=\mathrm{N}$ $/\left(1+\mathrm{NE}^{2}\right)$ 
$>$ Desired sample size $=\mathrm{n}=$ ?

$>$ Population $=\mathrm{N}$

$>$ Margin of error $=\mathrm{E}=0.05 \%$ (If we take confidence interval 95\%)

If the Total Eligible women are $\mathrm{N}=300$

\section{Sampling Method}

Non probability convenient sampling.

\section{Ethical Considerations}

This study was held keeping in view all the ethical considerations. Permission was taken from ethical committee of Afro Asian institute, Lahore, Punjab, Pakistan. The purpose of research was informed to the participants and if they any other information regarding research they were guided. Informed consent was signed by the Participants. Participants were informed that they have a right to participate or not to participate and they can even withdraw from the research anytime if they want. Participant's right for privacy was maintained. They were explained that their information will be kept confidential, no names or numbers were published.

\section{Data Collection Tool}

A self-administered, self-prepared questionnaire was used. The research tool used was well-organized questionnaire with close ended questions in it, as per True false to assess the Knowledge of Scabies among the women. Questionnaire was taken from the prior research articles. The questionnaire consisted of the demographic data of the participants such as name, Education, Ethnic group etc. The second part consisted of the closed ended questions related to Knowledge of Scabies.

\section{Data Collection Plan}

To collect the data, the questionnaire was developed. The questionnaire was then viewed by the supervisor. The permission was taken from the institutional Review Board. Then the researchers went to the research population and requested the community people for the participation in the research. A questionnaire was given to the participants with the consent form and they filled the questionnaire. Questionnaires were collected and qualify for the data analysis.

\section{Data Analysis}

The data was gathered and analysed on statistical data analysing software, SPSS version 21. The descriptive Results were analysed through Graphs, Tables in the form of Frequencies and proportions etc.

\section{Results}

\section{Demographic Data}

The Table1 reveals that $26.7 \%$ of the study participants were age group 15 to 25 years, $46.7 \%$ were age 26 to 35 Years and $26.7 \%$ were above the age of 35 years.

The findings of the Table 2 shows that $73.3 \%$ of the participants had education only up to primary while $26.7 \%$ were having Secondary education level

The Table 3 shows a very good knowledge level among the participants, $93.3 \%$ of the participants knew that scratching effect causes to Scabies while $6.7 \%$ did not know.

Table 1: Age of Participant

\begin{tabular}{|c|l|l|l|l|l|}
\hline \multicolumn{2}{|c|}{ Age } & Frequency & Percent & Valid Percent & Cumulative Percent \\
\hline \multirow{4}{*}{ Valid } & $15-25$ & 20 & 26.7 & 26.7 & 26.7 \\
\cline { 2 - 6 } & $26-35$ & 35 & 46.7 & 46.7 & 73.3 \\
\cline { 2 - 6 } & $>35$ & 20 & 26.7 & 26.7 & 100.0 \\
\cline { 2 - 6 } & Total & 75 & 100.0 & 100.0 & \\
\hline
\end{tabular}

Table 2: Education of Participant

\begin{tabular}{|l|l|l|l|l|l|}
\hline \multicolumn{2}{|c|}{ Education } & Frequency & Percent & Valid Percent & Cumulative Percent \\
\hline \multirow{3}{*}{ Valid } & Primary & 55 & 73.3 & 73.3 & 73.3 \\
\cline { 2 - 6 } & Secondary & 20 & 26.7 & 26.7 & 100.0 \\
\cline { 2 - 6 } & Total & 75 & 100.0 & 100.0 & \\
\hline
\end{tabular}

Table 3: The cause (etiology) of Scabies The effect of scratching

\begin{tabular}{|c|l|l|l|l|}
\hline & Frequency & Percent & Valid Percent & Cumulative Percent \\
\hline Valid yes & 70 & 93.3 & 93.3 & 93.3 \\
no & 5 & 6.7 & 6.7 & 100.0 \\
Total & 75 & 100.0 & 100.0 & \\
\hline
\end{tabular}


The Table 4 also shows that a very good number of participants that is $73.3 \%$ had knowledge that Skin is the main affected organ involved in scabies, while $26.7 \%$ did not know.

The Table 5 and graph also shows that a very good number of participants that is $86.7 \%$ had knowledge that itching at night and feeling heat is the main sign of scabies and $13.3 \%$ did not know the main signs and symptoms of scabies.

The findings of Table 6 and graph shows that a very good number of participants that is $80 \%$ had knowledge that mainly the covered body parts are affected in scabies and $20 \%$ did not know about this.
The Table 7 reveals that $66.7 \%$ of the study participants knew that scabies is transmitted through skin and $33.3 \%$ did not know about this.

When the participants were asked if teenagers are the only group who suffer from scabies? In response $86.7 \%$ participants said yes while $13.3 \%$ participants said no to this question (Table 8).

When the participants were asked about the classical signs of scabies, $73.3 \%$ of the study participants said that yes, burrow made by a mite within the skin is a classical sign of scabies while $26.7 \%$ said no to this question (Table 9).

Table 4: Skin is the Organ mainly affected by Scabies

\begin{tabular}{|rl|r|r|r|r|}
\hline & Frequency & Percent & Valid Percent & \multicolumn{2}{c|}{$\begin{array}{c}\text { Cumulative } \\
\text { Percent }\end{array}$} \\
\hline \multirow{3}{*}{ Valid } & yes & 55 & 73.3 & 73.3 & 73.3 \\
& no & 20 & 26.7 & 26.7 & 100.0 \\
& Total & 75 & 100.0 & 100.0 & \\
\hline
\end{tabular}

Table 5: Itching at night and feel the heat is main signs and Symptom of Scabies

\begin{tabular}{|ll|l|l|l|l|}
\hline & Frequency & Percent & Valid Percent & Cumulative Percent \\
\hline \multirow{2}{*}{ Valid nes } & 65 & 86.7 & 86.7 & 86.7 \\
& 10 & 13.3 & 13.3 & 100.0 \\
Total & 75 & 100.0 & 100.0 & \\
\hline
\end{tabular}

Table 6: Part that is often being covered are mainly affected by Scabies

\begin{tabular}{|ll|l|l|l|l|}
\hline & Frequency & Percent & Valid Percent & Cumulative Percent \\
\hline \multirow{2}{*}{ Valid nes } & 60 & 80.0 & 80.0 & 80.0 \\
no & 15 & 20.0 & 20.0 & 100.0 \\
Total & 75 & 100.0 & 100.0 & \\
\hline
\end{tabular}

Table 7: Scabies disease is transmitted through skin to skin contact and through clothes, towels, bed linen, and other things used by the patient

\begin{tabular}{|ll|l|l|l|l|}
\hline & & Frequency & Percent & Valid Percent & Cumulative Percent \\
\hline \multirow{4}{*}{ Valid } & yes & 50 & 66.7 & 66.7 & 66.7 \\
& no & 25 & 33.3 & 33.3 & 100.0 \\
& Total & 75 & 100.0 & 100.0 & \\
\hline
\end{tabular}

Table 8: Teenagers is the only group, Who can suffer from scabies

\begin{tabular}{|ll|l|l|l|l|}
\hline & Frequency & Percent & Valid Percent & Cumulative Percent \\
\hline \multirow{3}{*}{ Valid nes } & 65 & 86.7 & 86.7 & 86.7 \\
& 10 & 13.3 & 13.3 & 100.0 \\
& Total & 75 & 100.0 & 100.0 & \\
\hline
\end{tabular}

Table 9: The classical sign of scabies is the burrow made by a mite within the skin

\begin{tabular}{|ll|l|l|l|l|}
\hline & Frequency & Percent & Valid Percent & Cumulative Percent \\
\hline \multirow{4}{*}{ Valid } & yes & 55 & 73.3 & 73.3 & 73.3 \\
& 20 & 26.7 & 26.7 & 100.0 \\
Total & 75 & 100.0 & 100.0 & \\
\hline
\end{tabular}


The Table 10 reveals that $66.7 \%$ of the participants said yes to the question that scabies is diagnosed by clinical signs and symptoms while $33.33 \%$ said no in response.

When they were asked if Scabies is diagnosed through blood culture, in response $26.7 \%$ of the participants said that yes it is diagnosed through blood culture while $73.3 \%$ said that this is not diagnosed by blood culture (Table 11).

When they were asked if Scabies is diagnosed through stool analysis, in response $26.7 \%$ of the participants said that yes it is diagnosed through stool analysis while $73.3 \%$ said that this is not diagnosed by stool analysis (Table 12).
When they were asked if Scabies is diagnosed through microscopy of skin scraping, in response $46.7 \%$ of the participants said that yes it is diagnosed through microscopy of skin scraping while $53.3 \%$ said that this is not diagnosed by microscopy of skin scraping (Table 13).

The Table 14 reveals that $93.3 \%$ of the participants said yes that close contact with scabies patients not spreading the disease while $6.7 \%$ of the participants said no to the question.

The Table 15 reveals that $86.7 \%$ of the participants answered yes that high suspicion is required for scabies clinical diagnosis while $13.3 \%$ said no in response to this question.

Table 10: Scabies is diagnosed by Clinical signs and Symptoms

\begin{tabular}{|ll|l|l|l|l|}
\hline & Frequency & Percent & Valid Percent & $\begin{array}{l}\text { Cumulative } \\
\text { Percent }\end{array}$ \\
\hline \multirow{3}{*}{ Valid } & yes & 50 & 66.7 & 66.7 & 66.7 \\
& no & 25 & 33.3 & 33.3 & 100.0 \\
& Total & 75 & 100.0 & 100.0 & \\
\hline
\end{tabular}

Table 11: Scabies is Diagnosed by Blood Culture

\begin{tabular}{|ll|l|l|l|l|}
\hline & Frequency & Percent & Valid Percent & Cumulative Percent \\
\hline \multirow{4}{*}{ Valid } & yes & 20 & 26.7 & 26.7 & 26.7 \\
& no & 55 & 73.3 & 73.3 & 100.0 \\
Total & 75 & 100.0 & 100.0 & \\
\hline
\end{tabular}

Table 12: Scabies is Diagnosed by stool Analysis

\begin{tabular}{|ll|l|l|l|l|}
\hline & Frequency & Percent & Valid Percent & Cumulative Percent \\
\hline \multirow{4}{*}{ Valid } & yes & 20 & 26.7 & 26.7 & 26.7 \\
& 55 & 73.3 & 73.3 & 100.0 \\
& Total & 75 & 100.0 & 100.0 & \\
\hline
\end{tabular}

Table 13: Scabies is diagnosed by Microscopy of Skin Scraping

\begin{tabular}{|ll|l|l|l|l|}
\hline & Frequency & Percent & Valid Percent & Cumulative Percent \\
\hline \multirow{4}{*}{ Valid } & yes & 35 & 46.7 & 46.7 & 46.7 \\
& no & 40 & 53.3 & 53.3 & 100.0 \\
& Total & 75 & 100.0 & 100.0 & \\
\hline
\end{tabular}

Table 14: Close, prolonged personal contact with an infected person is not spreading Scabies therefore is common among family members

\begin{tabular}{|ll|l|l|l|l|}
\hline & & Frequency & Percent & Valid Percent & Cumulative Percent \\
\hline \multirow{4}{*}{ Valid } & yes & 70 & 93.3 & 93.3 & 93.3 \\
& no & 5 & 6.7 & 6.7 & 100.0 \\
& Total & 75 & 100.0 & 100.0 & \\
\hline
\end{tabular}

Table 15: High Suspicion Index is required for Clinical diagnosis

\begin{tabular}{|ll|l|l|l|l|}
\hline & Frequency & Percent & Valid Percent & Cumulative Percent \\
\hline \multirow{3}{*}{ Valid nes } & 65 & 86.7 & 86.7 & 86.7 \\
no & 10 & 13.3 & 13.3 & 100.0 \\
Total & 75 & 100.0 & 100.0 & \\
\hline
\end{tabular}


Table 16: Scabies can be Prevented by having Bath 2 times per day with soap and prevent direct contact with the patients

\begin{tabular}{|ll|l|l|l|l|}
\hline & Frequency & Percent & Valid Percent & Cumulative Percent \\
\hline \multirow{4}{*}{ Valid } & yes & 60 & 80.0 & 80.0 & 80.0 \\
& no & 15 & 20.0 & 20.0 & 100.0 \\
& Total & 75 & 100.0 & 100.0 & \\
\hline
\end{tabular}

Table 17: Drying mattress and pillow prevent scabies

\begin{tabular}{|ll|l|l|l|l|}
\hline & Frequency & Percent & Valid Percent & Cumulative Percent \\
\hline \multirow{3}{*}{ Valid } & yes & 70 & 93.3 & 93.3 & 93.3 \\
& no & 5 & 6.7 & 6.7 & 100.0 \\
& Total & 75 & 100.0 & 100.0 & \\
\hline
\end{tabular}

The findings of Table 16 shows that a very good number of participants that is $80 \%$ had knowledge that scabies can be prevented by taking bath 2 times a day with sope and proper contact precaution and $20 \%$ did not know about this.

The findings of Table 17 shows that a very good number of participants that is $93.3 \%$ had knowledge that drying of mattress and pillow can prevent scabies and $6.7 \%$ did not know about this.

\section{Discussion}

As mention in intro scabies is a parasitic skin infestation it occurs worldwide being most common in condition of overcrowding, poverty and poor hygiene. (Sule, Hassan, Gyang, \& Yakuba, 2015). During this study the knowledge of scabies was good among the participants in contrast to another study given below where they found that among 1260 samples only $20.6 \%$ had adequate knowledge regarding scabies and its management.

Around $14.56 \%$ individuals had previous exposure to scabies. $33.4 \%$ of the samples wrongly reported that scabies is a non-curable disease. They realised that around $46.7 \%$ victims are currently following appropriate anti - scabies prophylaxis that includes allethrin, permethrin and ivermectin. The researchers concluded that rural communities require more information and education regarding skin related contagious diseases and their management measures (Rana et al., 2007)

According to our study $26.7 \%$ of study participants were age group 15-25 years, $46.7 \%$ were age 26-35 years and $26.7 \%$ were the age of above $35 \%$ of participants had education only up to primary while $26.7 \%$ were having secondary education level. $93.3 \%$ of the participants knew that scratching effect causing to scabies that shows very good knowledge level among the participants while $6.7 \%$ did not know. 93.3\% had knowledge that drying of mattress and pillow can prevent scabies and $6.7 \%$ did not know about this that shows their excellent knowledge.
$73.3 \%$ had knowledge that skin is the main effected organ involve in scabies while $26.7 \%$ did not know. This also show good knowledge among the participants regarding the skin is main effected organ. $86.7 \%$ had knowledge that itching at night and feeling heat is the main sign of scabies and $13.3 \%$ did not know the main sign and symptoms of scabies. $80 \%$ participants had knowledge the cover body parts are mainly effected in scabies and $20 \%$ did not know about this. All these percentages show very good knowledge among the participants.

$66.7 \%$ study participants knew that scabies is transmitted through skin to skin contact and $33.3 \%$ did not know about this. This shows adequate knowledge among participants about the transmission of disease. $73.3 \%$ study participants said that yes burrow made by mite within this skin is a classical sign of scabies while $26.7 \%$ said no. When they were asked about the diagnosis of scabies only $26.7 \%$ participants knew that it is diagnose through the blood culture and $73.3 \%$ did not know. This shows poor knowledge among participants about the diagnosis of scabies.

\section{Conclusion}

Overall the participants had god knowledge regarding some questions such as the cause of disease and the main organ involved in it. The knowledge was poor about the diagnostic procedure for the Scabies. More detailed studied are required.

\section{Limitations}

Small sample size, the study findings cannot be generalized

Descriptive study which is weak study

Time limitations, as students we do not have long time to have depth explorations.

\section{References}

Buehlmann M, Beltraminelli H, Strub C, Bircher A, Jordan X, Battegay M et al. (2009) Scabies outbreak in an intensive care unit with 1,659 exposed individuals - key factors for 
controlling the outbreak. Infection Control and Hospital Epidemiology 30(4): 354-360.

Hay R, Steer A, Engelman D \& Walton S (2012) Scabies in the developing world-its prevalence, complications, and management. Clinical Microbiology and Infection 18(4): 313-323.

Lapeere H, Naeyaert J-M, De Weert J, De Maeseneer J et al (2008) Incidence of scabies in Belgium. Epidemiology and Infection 136(3): 395-398.

Mumtaz Y, Zafar M et al. (2014) Knowledge Attitude and Practices of Mothers about Diarrhea in Children under 5 years. Journal of Dow University of Health Sciences 8(1).

Patel JK, Vyas AP, Berman B and Vierra M. (2010) Incidence of childhood dermatosis in India. Skinmed 8(3): 136-142.

Patrick I, Patel M, Fenwick S (2007) SRA Assessment of zoonotic diseases in Indonesia.
Rana U, Yadav R, Geetharani P, Ponnuswamy A, Amanullah MM, Sathyamoorthi K et al. (2007) Correlation and path coefficient analysis in chickpea (Cicer arietinum L.). International Journal of Plant Sciences.

Rathi SK, Rathi HS, Lakhani H, Hansotia MF (2001) Awareness about scabies among general medical practitioners (GPs) of Karachi, Pakistan. Journal-Pakistan Medical Association. 51(10): 370-372.

Strong M \& Johnstone P (2011) Cochrane review: interventions for treating scabies. Evidence-Based Child Health: A Cochrane Review Journal 6(6): 1790-1862.

Sule HM, Hassan ZI, Gyang MD et al. (2015) Knowledge of Scabies Among a Cohort of Medical Students.

Zeba N, Shaikh DM, Memon KN et al (2014) Scabies in relation to hygiene and other factors in patients visiting Liaquat University Hospital, Sindh, Pakistan. Age 9: 10-19. 